Old Dominion University

ODU Digital Commons

7-2017

\title{
Robustness of Observation-Based Decadal Sea Level Variability in the Indo-Pacific Ocean
}

\author{
A. G. Nidheesh \\ M. Lengaigne \\ J. Vialard \\ T. Izumo
}

A. S. Unnikrishnan

See next page for additional authors

Follow this and additional works at: https://digitalcommons.odu.edu/oeas_fac_pubs

Part of the Geology Commons, and the Oceanography Commons

\section{Original Publication Citation}

Nidheesh, A. G., Lengaigne, M., Vialard, J., Izumo, T., Unnikrishnan, A. S., Meyssignac, B., . . Montegut, C. D. (2017). Robustness of observation-based decadal sea level variability in the Indo-Pacific Ocean. Geophysical Research Letters, 44(14), 7391-7400. doi:10.1002/2017gl073955

This Article is brought to you for free and open access by the Ocean \& Earth Sciences at ODU Digital Commons. It has been accepted for inclusion in OES Faculty Publications by an authorized administrator of ODU Digital Commons. For more information, please contact digitalcommons@odu.edu. 


\section{Authors}

A. G. Nidheesh, M. Lengaigne, J. Vialard, T. Izumo, A. S. Unnikrishnan, B. Meyssignac, B. Hamlington, and C. de Boyer Montegut 


\section{Geophysical Research Letters}

\section{RESEARCH LETTER}

10.1002/2017GL073955

Key Points:

- Pacific Ocean decadal sea level variability is robust and largely driven by decadal modulation of ENSO and Modoki

- Indian Ocean decadal sea level variability (either related to or independent from the Pacific) is inconsistent across observation-based sea level products

Supporting Information:

- Supporting Information S1

Correspondence to:

A. G. Nidheesh,

gnidheesh@locean-ipsl.upmc.fr

\section{Citation:}

Nidheesh, A. G., M. Lengaigne, J. Vialard, T. Izumo, A. S. Unnikrishnan,

B. Meyssignac, B. Hamlington, and C. de Boyer Montegut (2017), Robustness of observation-based decadal sea level variability in the Indo-Pacific Ocean, Geophys. Res. Lett., 44, 7391-7400, doi:10.1002/2017GL073955.

Received 25 APR 2017

Accepted 10 JUL 2017

Published online 30 JUL 2017

(c)2017. American Geophysical Union. All Rights Reserved.

\section{Robustness of observation-based decadal sea level variability in the Indo-Pacific Ocean}

\author{
A. G. Nidheesh ${ }^{1,2}$ (D) M. Lengaigne ${ }^{1,3}$ (D) J. Vialard' ${ }^{1}$, T. Izumo ${ }^{1,3}$ (D) A. S. Unnikrishnan², \\ B. Meyssignac ${ }^{4}$ iD, B. Hamlington 5 iD, and C. de Boyer Montegut ${ }^{6}$
}

${ }^{1}$ LOCEAN-IPSL, Sorbonne University (UPMC, University Paris 06)-CNRS-IRD-MNHN, Paris, France, ${ }^{2}$ CSIR-National Institute of Oceanography, Goa, India, ${ }^{3}$ Indo-French Cell for Water Sciences, IISC-NIO-IITM-IRD Joint International Laboratory, CSIR-NIO, Goa, India, ${ }^{4}$ LEGOS, CNES, CNRS, IRD, UPS, Université de Toulouse, Toulouse, France, ${ }^{5}$ Department of Ocean, Earth and Atmospheric Sciences, Old Dominion University, Norfolk, Virginia, USA, 'aboratoire d'Océanographie Physique et Spatiale, UBO/Ifremer/CNRS/IRD, Brest, France

Abstract We examine the consistency of Indo-Pacific decadal sea level variability in 10 gridded, observation-based sea level products for the 1960-2010 period. Decadal sea level variations are robust in the Pacific, with more than $50 \%$ of variance explained by decadal modulation of two flavors of El Niño-Southern Oscillation (classical ENSO and Modoki). Amplitude of decadal sea level variability is weaker in the Indian Ocean than in the Pacific. All data sets indicate a transmission of decadal sea level signals from the western Pacific to the northwest Australian coast through the Indonesian throughflow. The southern tropical Indian Ocean sea level variability is associated with decadal modulations of ENSO in reconstructions but not in reanalyses or in situ data set. The Pacific-independent Indian Ocean decadal sea level variability is not robust but tends to be maximum in the southwestern tropical Indian Ocean. The inconsistency of Indian Ocean decadal variability across the sea level products calls for caution in making definitive conclusions on decadal sea level variability in this basin.

\section{Introduction}

Identifying, understanding, and projecting sea level changes are of critical importance for assessing its socioeconomic and environmental impacts and for planning and adaptation strategies. This is particularly true for the tropical Indo-Pacific ocean, which hosts a large number of highly populated low-lying coastal zones. China, India, Bangladesh, Vietnam, and Indonesia are, for instance, the top five countries for population at risk from sea level rise, with more than 350 million people involved [Neumann et al., 2015]. While the global mean sea level has been rising consistently at a rate of about $3.3 \mathrm{~mm} \mathrm{yr}^{-1}$ over the last two decades [e.g., Fasullo et al., 2016], regional sea level changes can deviate considerably from this global mean rate, to the point that local and global trends can differ in sign at some locations [Stammer et al., 2013]. This spatially nonuniform pattern in regional sea level trends mainly arises from changes in surface wind patterns in response to both natural climate variability (especially at decadal/multidecadal time scales) and anthropogenic climate change [Stammer et al., 2013]. Identifying the sea level imprint of natural climate variability, especially at decadal time scales, is hence crucial for separating the effects of natural climate variability and anthropogenic forcing on observed sea level change.

The El Niño-Southern Oscillation (ENSO) is the leading mode of interannual climate variability and involves large sea level signals in the tropical Pacific [e.g., Widlansky et al., 2015]. The Interdecadal Pacific Oscillation (IPO), for which the decadal ENSO modulation is an active driver [Power et al., 1999; Newman et al., 2016], is a major partaker of low-frequency sea level variations in the Pacific Ocean [e.g., Bromirski et al., 2011; Meyssignac et al., 2012b; Hamlington et al., 2013; Frankcombe et al., 2015; Palanisamy et al., 2015], inducing opposite sea level decadal signals in the western tropical Pacific and central/eastern equatorial Pacific. These decadal variations strongly contribute to regional sea level trends over the past two decades, including the accelerated (reduced) rise relative to the global rate in the western (eastern) tropical Pacific [e.g., Merrifield, 2011; Zhang and Church, 2012; Moon et al., 2013; Frankcombe et al., 2015; Hamlington et al., 2014]. El Niño events come in two primary "flavors," with maximum surface temperature and sea level anomalies (SLA) occurring either in the east or central Pacific. Central Pacific El Niños have been nicknamed Modoki events [Ashok et al., 2007]. The decadal modulation of Modoki events is associated with decadal sea 
level variation in the northern Pacific, referred to as the North Pacific Gyre Oscillation [Di Lorenzo et al., 2010]. Behera and Yamagata [2010, hereafter BY2010] also suggested, based on an 8 year satellite altimetry record analysis, that central Pacific decadal sea level variations are strongly related to Modoki decadal modulation.

While decadal climate variability and its sea level imprint are rather well documented in the Pacific, this is not the case in the Indian Ocean (IO hereafter), primarily because of the scarcity of long-term observations in this basin [e.g., Han et al., 2014]. There is a well-established oceanic bridge at interannual [e.g., Feng et al., 2003] and decadal time scales between the western equatorial Pacific and southeast IO [Feng et al., 2004, 2010; Trenary and Han, 2013; Schwarzkopf and Böning, 2011; Nidheesh et al., 2013, hereafter N2013], via the coastal waveguide in the Indonesian throughflow region (in the following, we always refer to the connection between the Pacific and IO via the Indonesian Throughflow as the "oceanic bridge"). Apart from this oceanic bridge, there is no consensus on how the Pacific influences 10 decadal sea level variability through atmospheric teleconnections. Based on the short 1993-2006 altimeter record, Lee and McPhaden [2008] suggested that the IPO is associated with southern tropical IO decadal sea level variations through atmospheric teleconnections. However, using an ocean model simulation, N2013 showed that this apparent IPO control on IO decadal sea level variability breaks down over the longer period of 1966-2007. Along the same lines, the respective influence of remote and local wind forcing on decadal sea level variations in the southern tropical IO appears to vary considerably depending on the period and data set [e.g., Schwarzkopf and Böning, 2011; Trenary and Han, 2013; Zhuang et al., 2013; Li and Han, 2015; N2013]. Recent studies suggest that the main cause of the recent "hiatus" in global surface warming is associated with an increase in the heat uptake by the Pacific during a negative IPO phase and that excess heat was largely transferred to the IO through the oceanic bridge [Lee et al., 2015; Nieves et al., 2015]. This is a striking example of how natural decadal climate variability obscures the anthropogenic climate change and a strong incentive to better understand IO decadal sea level (and heat content) variations and their linkage to the Pacific decadal variability.

The study of Indo-Pacific decadal sea level variability requires gridded data sets that span several decades. The modern satellite altimetry offers sea level measurements with a near-global coverage but only spans 24 years. On the other hand, tide gauge sea level measurements are confined to coastal regions and islands, preventing a thorough assessment of open ocean variability. The lack of long-term, near-global sea level data hence prompted the scientific community to develop a number of different gridded sea level data sets, providing global sea level estimates for at least the past 50 years. This includes reconstructions [e.g., Church et al., 2004; Church and White, 2011; Hamlington et al., 2011; Meyssignac et al., 2012a] that combine spatial patterns derived from the altimetry or ocean models with longer time series from tide gauge records to estimate sea level over multidecadal epochs. N2013 showed that steric sea level variations in the tropical Indo-Pacific are primarily driven by thermal variations in the upper thousand meters. Hence, the historical in situ subsurface temperature data-largely a few expendable bathythermograph lines_can be interpolated in space to estimate thermosteric sea level changes [e.g., Levitus et al., 2012] or built into an ocean reanalysis to simulate sea level over the historical period. Caveats for those products (reconstructions and reanalyses) include sparse observational coverage, assumptions in the interpolation method, model errors, and errors in decadal wind fluctuation estimates [e.g., N2013]. This can lead to significant biases in the representation of sea level variability in those observation-based data.

To our knowledge, there is currently no thorough evaluation of the consistency of Indo-Pacific decadal sea level variations among available products. In the present paper, we examine 10 gridded sea level products available for the period of 1960-2010 (three reanalyses, six reconstructions, one in situ-based product) to address the following questions. Are the dominant patterns of Pacific decadal sea level variability identified in earlier studies robust across these different gridded sea level data sets? Is the sea level imprint of the Pacific decadal climate variability robust over the IO? Is there any robust Pacific-independent decadal sea level variability in the IO?

\section{Data and Methods}

We use 10 gridded sea level products available over their overlapping period of 1960-2010 to investigate if they display coherent decadal sea level variability over the Indo-Pacific region. A general description of the products is given below, but a more thorough description of each product is provided in the supporting information. We used thermosteric sea level computed from the World Ocean Data (hereafter WO) (Levitus et al. 
[2012] for details). We also used three ocean reanalyses: Ocean Reanalysis System 4 from the European Centre for Medium-Range Weather Forecasts (hereafter OR) [Balmaseda et al., 2013],Simple Ocean Data Assimilation (hereafter SO) [Carton and Giese, 2008], and German contribution to the consortium for Estimating the Circulation and Climate of the Ocean (hereafter GE) [Köhl and Stammer, 2008]. We further considered six different sea level reconstructions. Three of them are based on altimetry-derived basis functions [Church and White, 2011, hereafter CW; Hamlington et al., 2011, 2012, hereafter HA; Meyssignac et al., 2012a, hereafter $\mathrm{M} 1]$. Since sea level reconstructions are sensitive to the data set from which the basis functions are derived [see Meyssignac et al., 2012a], we also used three additional reconstructions similar to Meyssignac et al. [2012a] but whose basis functions are derived from the three ocean reanalyses mentioned above (i.e., OR (M2), SO (M3), and GE (M4)).

All the above data sets have a monthly resolution. We interpolated each data set to a regular $2.5^{\circ} \times 2.5^{\circ}$ grid. Interannual and decadal (defined as the variability above 7 year periodicity) components of variability are extracted using the seasonal trend decomposition procedure described in Cleveland et al. [1990]. Some of the products we use (WO and reanalyses) do not account for the spatially uniform sea level rise due to changes in ocean mass (while reconstructions do). Since this study focuses on regional sea level variability, the globally averaged sea level time series (Figure S1) is subtracted from each grid point for all data sets.

The indices of the leading decadal climate modes in the tropical Pacific (classical ENSO and Modoki decadal variations) are defined through an empirical orthogonal function (EOF) analysis of Hadley Centre Sea Ice and Sea Surface Temperature data set (HadISST) [Rayner et al., 2003], a typical method of climate mode indices definition used in previous studies [e.g., Newman et al., 2003; Nidheesh et al., 2017]. These time series are strongly correlated with the decadally filtered classical ENSO and Modoki indices ( 0.97 and 0.76 correlation respectively, Figure S2), and similar results were obtained when using those classical indices (not shown).

We consider the ensemble mean as an indicator of consensus variability in the 10 sea level products. To assess the interproduct consistency, we computed the interproduct spread as the square root of the mean squared deviations from the ensemble mean, averaged over products and time. We then defined a metric called the agreement ratio as the spread divided by the standard deviation of the ensemble mean variability. This agreement ratio is used as a metric that summarizes the spread in variability between the products relative to the mean amplitude of the variability (computational details of agreement ratio are given in the supporting information).

\section{Results}

Figure 1a displays the standard deviation of ensemble mean (for the 10 products) decadal sea level variability in the Indo-Pacific ocean. Strongest decadal sea level variations (2 to $3 \mathrm{~cm}$ ) occur in the western tropical Pacific, as well as east of Japan in the Kuroshio extension region. Weaker decadal sea level variability, relative maxima $(\sim 1 \mathrm{~cm})$, occurs along the West Coast of America and in the central Pacific midlatitudes of both hemispheres (around $30^{\circ}$ ). In general, the amplitude of $\mathrm{IO}$ decadal sea level variability is weaker than Pacific variability, with the largest signals along the western Australian coast $(\sim 2 \mathrm{~cm})$, in the southern tropical 10 $(\sim 1.5 \mathrm{~cm})$, in the eastern equatorial IO and along the rim of Bay of Bengal (BoB, $\sim 1 \mathrm{~cm})$. Similar regions of maximum decadal variability are found in the shorter altimeter data (see Figure S3).

The white (respectively black) stippling in Figure 1a indicates grid points where the "agreement ratio" defined in section 2 is less than 0.5 (respectively 1), i.e., where the disagreement between products is small compared to the sea level ensemble mean decadal variability. In the Pacific, regions of large decadal sea level variations are generally consistent among products, except in the Kuroshio extension region (decadal variability in this region is largely due to oceanic intrinsic variability [Serazin et al., 2015] which is not the same in different models and very difficult to tame to observations even when assimilating data). This agreement is particularly strong (white stippling) in the western and eastern tropical Pacific. The picture is very different in the IO where the analyzed products exhibit inconsistent decadal sea level variations in most of the regions. A large area of moderate interproduct agreement (black stippling) is, however, found along the west coast of Australia. Sparse black stippling indicates a modest interproduct agreement in the southern tropical IO. In contrast, decadal sea level variations in the eastern equatorial $I O$ and in the $\mathrm{BoB}$ are not consistent among the products. Figure $1 \mathrm{~b}$ displays the zonal distribution of the agreement ratio averaged over $20^{\circ} \mathrm{S}-20^{\circ} \mathrm{N}$ in the Indo-Pacific region. While this ratio is nearly 0.5 in the western and eastern tropical Pacific and 1 in the 
a) Std (Ens. Mean SLA)

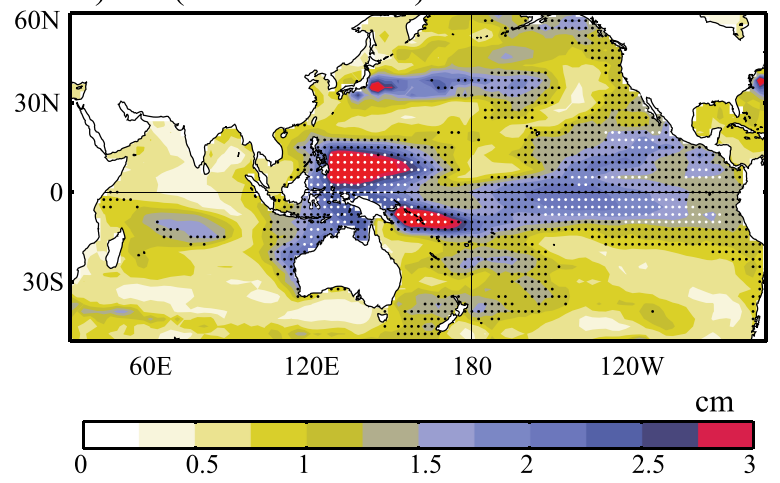

b) 20N-20S Mean Agreement Ratio

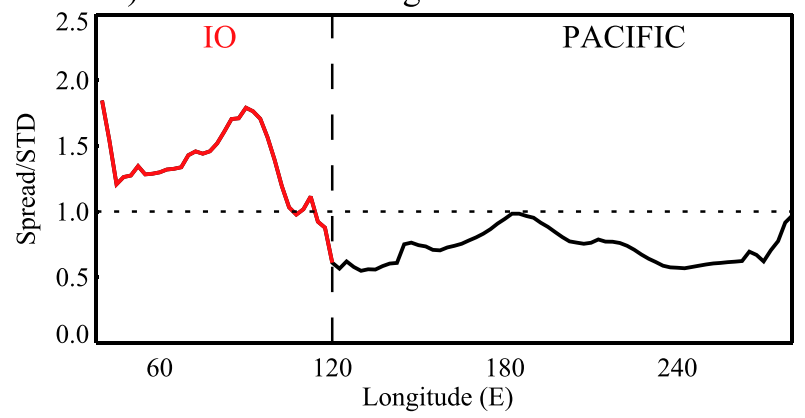

Figure 1. (a) Standard deviation (std) of the ensemble mean decadal sea level variability from the 10 gridded products analyzed (color). Black (respectively white) dots indicate regions where the agreement ratio is below 1 (respectively 0.5 ). A small agreement ratio means that the differences in variability between the products (spread) are small relative to the mean amplitude of variability (std) (see section 2 and supporting information for details). (b) Zonal distribution of the $20^{\circ} \mathrm{N}-20^{\circ} \mathrm{S}$ averaged agreement ratio in the Indo-Pacific. central tropical Pacific, it ranges from 1 to 2 in the tropical 10 west of $110^{\circ}$ E. This simple diagnostic clearly illustrates the larger interproducts spread in the tropical 10 than in the tropical Pacific, except along the west Australian coast.

Figures $2 \mathrm{a}$ and $2 \mathrm{~d}$ display the ensemble average patterns of the first two EOFs of decadal sea level variability, performed over the Pacific domain $\left(120^{\circ} \mathrm{E}-70^{\circ} \mathrm{W}, \quad 45^{\circ} \mathrm{S}-60^{\circ} \mathrm{N}\right)$ for the 1960-2010 period. These first two EOFs collectively explain more than $50 \%$ (Figures S4 and S5) of Pacific decadal sea level variance for all products (70\% on average; see Figure 2). The first EOF pattern (Figure 2a, 54\% of variance on average) in the Pacific is reminiscent of the sea level signature of the positive IPO phase [e.g., Meyssignac et al., 2012a; Hamlington et al., 2013]. This is confirmed by the strong correlation of the corresponding ensemble mean principal component (PC) with the decadal ENSO index ( $r=0.94$, Figure $2 b$ ), with a very small interproducts spread (correlation above 0.8 for all products except $\mathrm{GE}$; see Figure S4). The abnormally weak trade winds during the decadal ENSO positive phase (Figure S2) induce a large-scale sea level seesaw in the tropical Pacific, with positive anomalies in the central/eastern and negative anomalies in the western tropical Pacific. The positive SLA in the eastern Pacific propagate poleward along the American coast as coastal Kelvin waves and westward into the basin as Rossby waves, with faster Rossby wave propagation at low latitudes explaining the V-shaped pattern with larger offshore extent in the tropics [e.g., N2013]. This mode also exhibits a negative sea level signature in the central Pacific midlatitudes of both hemispheres (around $30^{\circ}$ ), via atmospheric teleconnections between the tropical Pacific and surface wind-stress curl in the mid-latitude low-pressure regions [e.g., Moon et al., 2013]. A narrow negative sea level signal is also evident off the Japanese coast in the Kuroshio extension region. As in Figure 1, stippling indicates regions of low agreement ratio (a good interproducts agreement) but here for the decadal sea level signal projected on that EOF. This stippling indicates that the sea level signal associated with decadal ENSO is very robust in the regions discussed above (see also individual patterns in Figure S4). The pattern correlation between individual EOFs and the ensemble mean EOF exceeds 0.8 for all products except GE (0.65), highlighting the robustness of this EOF pattern in the Pacific across the products (Figure 2c).

The second EOF of decadal sea level in the Pacific (Figure $2 \mathrm{~d}, \sim 18 \%$ of variance on average) is characterized by a broad positive SLA in the western and central tropical Pacific $\left(\sim 15^{\circ} \mathrm{S}\right.$ to $\left.\sim 5^{\circ} \mathrm{N}\right)$ and a narrow band of positive SLA off the east coast of Japan. Negative SLA are evident in the northwest tropical Pacific (southeast of Philippines) and along the West Coast of tropical south America (Figure 2d). This pattern is reminiscent of the one described as the imprint of decadal Modoki variability in BY2010. The 0.81 correlation between the corresponding ensemble PC and the decadal Modoki index (Figure 2e) further confirms that this pattern is associated with decadal modulation of Modoki. The interproduct consistency for this second mode is, however, weaker than that of the first EOF (no white stippling), with an interproducts agreement mostly in the 
a) Ensemble Mean EOF1

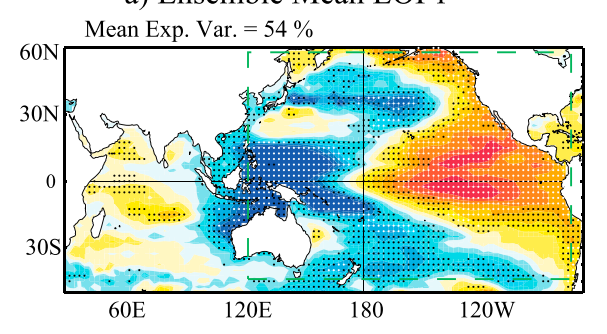

d) Ensemble Mean EOF2

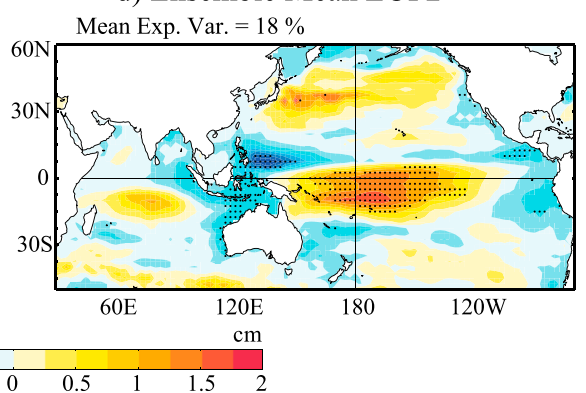

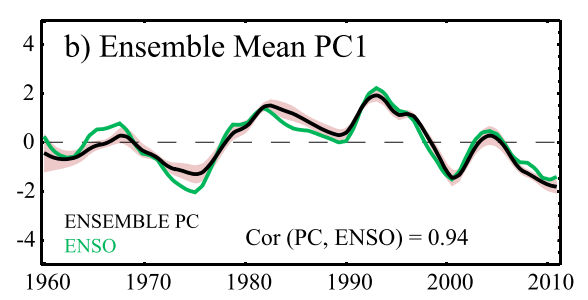

c) EOF1 Pattern Corr. with panel a

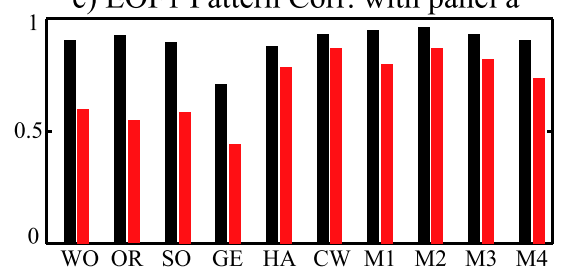

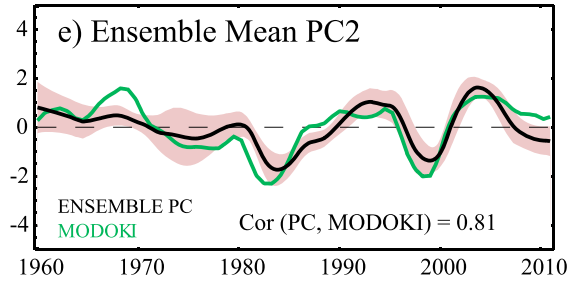

f) EOF2 Pattern Corr. with panel d

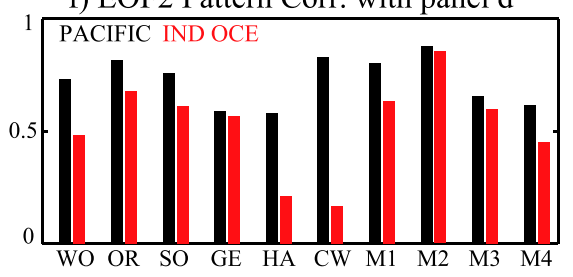

Figure 2. Ensemble mean of the (a) first and (d) second EOFs of Pacific decadal sea level variations across the 10 analyzed gridded products (color). The EOFs are computed over the domain highlighted by the green frame in Figure $2 \mathrm{a}$ (with a mask to discard western Atlantic). The pattern outside the EOF domain is obtained by linearly regressing the decadal sea level anomalies onto the corresponding normalized principal component (PC) for each product. As in Figure 1a, black (white) dots indicate regions where the spread among the products is smaller (twice smaller) than the mean amplitude associated with that EOF (see supporting information for details). (b, e) Corresponding ensemble mean PCs (black curves) with the shading indicating \pm 1 standard deviation. Decadal ENSO and Modoki indices are displayed by the green curves on Figures $2 \mathrm{~b}$ and 2e, respectively. ( $\mathrm{c}, \mathrm{f}$ ) Bar diagram showing the Pacific (black) and $\mathrm{IO}$ (red) pattern correlation between the EOF pattern for individual product and the ensemble mean EOF pattern shown on Figures 2a and $2 \mathrm{~d}$.

central and western tropical Pacific (stippling in Figure 2d; see also individual patterns in Figure S5). Individual EOF2 patterns are also less consistent with the ensemble mean pattern for the Pacific, with lower pattern correlations, ranging from 0.4 to 0.8 (Figure 2f). The spread of the second PCs is also larger than that of the first PCs (Figures $2 \mathrm{~b}$ and $2 \mathrm{e}$ ), especially before 1980, with correlations for individual products ranging from 0.4 to 0.85 (Figure $\mathrm{S} 5$ ).

In the rest of the paper, we will refer to EOFs 1 and 2 in Figure 2 as decadal ENSO and decadal Modoki, respectively. Note, we do not imply that decadal variations in the tropical Pacific are the sole drivers of, e.g., IPO variability, for which stochastic atmospheric forcing at midlatitudes, for instance, also matters [e.g., Newman et al., 2016]. However, recent experiments with coupled models indicate that specifying SST anomalies in the central and eastern equatorial Pacific allows reproducing global patterns of decadal variability, including in the IO [e.g., Kosaka and Xie, 2013; Dong et al., 2016]. This is a strong indication that equatorial Pacific decadal SST variations associated with ENSO and Modoki are the common forcing source that establishes the global patterns associated with Pacific decadal climate variability.

These dominant modes in Pacific decadal sea level variability are associated with signals in the IO. While the oceanic bridge associated with decadal ENSO fluctuations [e.g., Feng et al., 2010] is robust across products, that associated with Modoki (BY2010) is more variable. The sea level signal in the southern tropical IO, attributed by Lee and McPhaden [2008] to a remote control of the wind stress curl in this region (Figure S2) through atmospheric teleconnections from the Pacific, appears in association with both decadal ENSO and Modoki, 
a) SLA exp. variance (ENSO, Modoki)

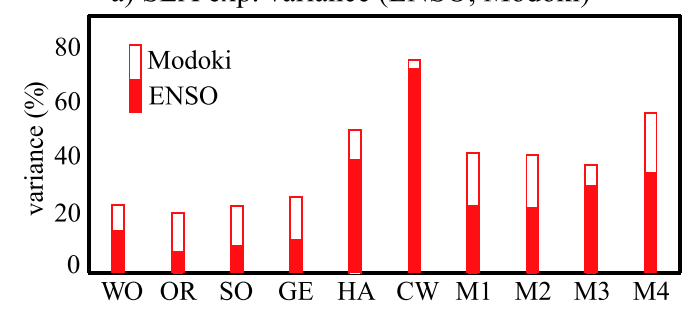

b) Std (Ens. Mean Pac-indep. SLA)

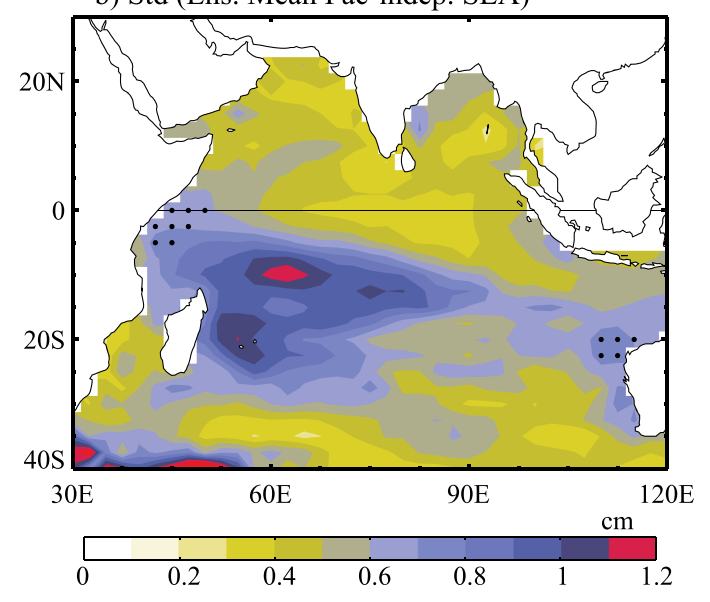

Figure 3. (a) Bar diagram showing the respective contribution of decadal ENSO (red-filled bar) and Modoki (unfilled) to the total decadal sea level variance in the 10 for each data. (b) Standard deviation of the ensemble mean decadal sea level variability in the $\mathrm{IO}$, once the variability associated with decadal ENSO and Modoki is removed through a multilinear regression. A similar stippling as in Figure $1 \mathrm{a}$ is applied on Figure $3 \mathrm{~b}$ to indicate the regions where this Pacific-independent variability across the products is robust. although the signal is consistent (but with sparse stippling) across the products only for ENSO (see stippling in Figures $2 \mathrm{a}$ and $2 \mathrm{~d}$ ). The weak negative sea level imprint of both modes in the eastern equatorial 10 and along the rim of $\mathrm{BoB}$ is not robust (Figures $2 \mathrm{a}$ and $2 \mathrm{~d}$ ). The stippling in Figures $2 a$ and $2 d$ in fact indicates that the sea level signature of decadal ENSO and Modoki is more variable in the 10 than in the Pacific. The IO sea level pattern related to ENSO is quite variable from one product to another (pattern correlations from 0.4 to 0.8 , Figure $2 c$ ). These interproduct differences are even larger for IO decadal Modoki signals (pattern correlations from 0.1 to 0.8 : $\mathrm{HA}$ and $\mathrm{CW}$ are outliers, being the only two products that do not indicate a decadal Modoki signature in the southern tropical IO: Figure S5). Overall, decadal ENSO and Modoki sea level signatures have varying amplitudes but always a consistent sign in key regions of the Pacific and have a larger spread that even changes sign in the IO (Figure S6).

The above analyses show that, although variable among products, both decadal ENSO and Modoki have a remote influence on decadal sea level variations in the $\mathrm{IO}$. Figure $3 \mathrm{a}$ further shows the percentage of $\mathrm{IO}$ decadal sea level variance explained by these Pacific climate modes. The Pacific influence is systematically larger in reconstructions ( $40 \%$ on average up to $80 \%$ in CW) as compared to other products ( $20 \%$ average), most likely because the EOF truncation used in reconstructions yields minimum small-scale variability than in reanalyses or in situ data. Figure 3a hence illustrates that for all products except CW, 50 to $80 \%$ of the IO decadal sea level variance is independent from the two leading modes of Pacific decadal variability. This calls for a specific assessment of the consistency of Pacific-independent IO decadal sea level variability among different products. To that end, we estimated the Pacific-independent IO decadal sea level variability by subtracting signals linearly related to decadal ENSO and Modoki indices (which are orthogonal by our definition based on EOFs) from the IO decadal sea level signal. Figure $3 \mathrm{~b}$ displays the standard deviation of this ensemble mean Pacific-independent sea level signal in the IO. The largest signals are found in a broad region in the southwestern tropical and subtropical $1 \mathrm{O}$, between $5^{\circ} \mathrm{S}$ and $30^{\circ} \mathrm{S}$, which partly overlaps the region where Pacific climate modes imprint their sea level signatures (see Figures $2 \mathrm{a}$ and $2 \mathrm{~d}$ ). There is, however, no consensus on this Pacific-independent variability depicted by each product (as revealed by very scarce stippling in Figure $3 \mathrm{~b}$ and varying individual patterns in Figure 57). While most products suggest a large Pacificindependent decadal sea level variability in the $\mathrm{IO}$, this variability is thus not consistent across the products.

Some of the diagnostics above suggest a different behavior from sea level reconstructions relative to reanalyses and WO. First, the percentage of $\mathrm{IO}$ decadal sea level variance explained by decadal ENSO and Modoki fluctuations is notably higher in reconstructions (on average $48 \%$ ) than reanalyses and WO (23\%, Figure 3a). Second, the IO decadal ENSO pattern also tends to be different for reanalyses and WO than for reconstructions (red bars in Figure 2c). We hence display the ensemble average patterns of IO sea level signature 

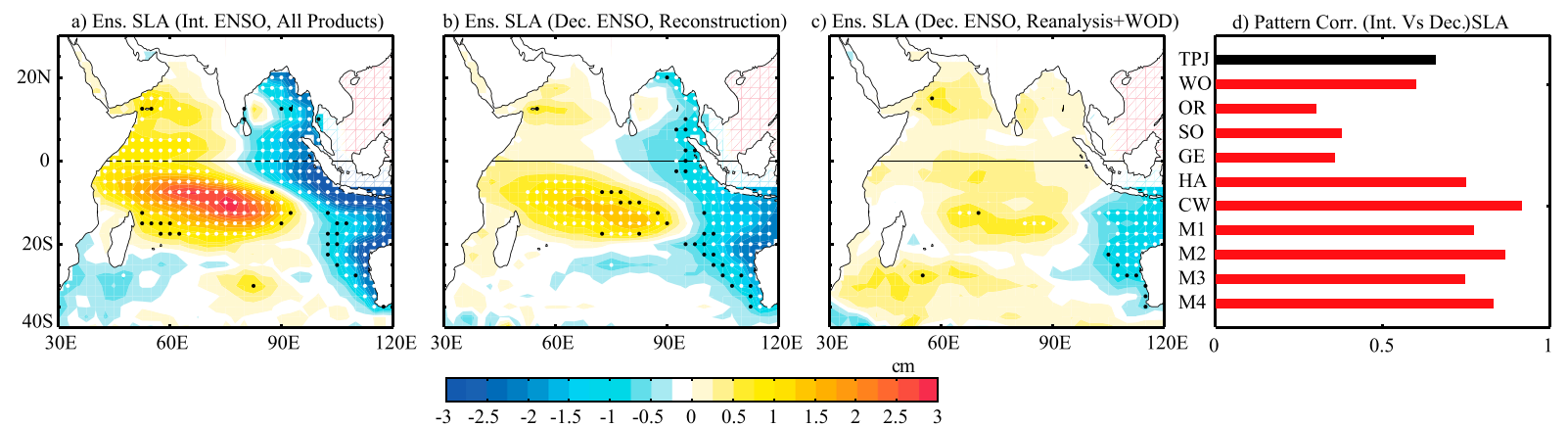

Figure 4. (a) Ensemble mean of IO sea level anomalies (SLA) linearly related to interannual ENSO index for the 10 analyzed gridded products. Ensemble mean of IO SLA linearly related to decadal ENSO for (b) the six sea level reconstructions and (c) the three ocean reanalyses and WO. (d) Pattern correlation between the IO SLA associated with interannual and decadal ENSO for each product. A high correlation indicates that the interannual and decadal ENSO signatures have similar patterns in the $\mathrm{IO}$ for a given product.

associated to decadal ENSO separately for reconstructions and rest of the products in Figures $4 \mathrm{~b}$ and $4 \mathrm{c}$. The signal transmitted via the oceanic bridge to the west coast of Australia is consistent across all the products at both interannual and decadal time scales (Figures $4 a-4 c$ ). On the other hand, the sea level signature associated to atmospheric teleconnection between the Pacific and southern tropical IO, suggested by Lee and McPhaden [2008], is hardly visible in reanalyses and WO (Figure 4c). In reconstructions, the IO decadal ENSO sea level signature (Figure 4b) largely resembles that of interannual ENSO (Figure 4a), which itself is very similar to the IO Dipole (IOD) signature [e.g., Webster et al., 1999] (there is a tendency for El Niño events to trigger positive IODs [e.g., Annamalai et al., 2003]). High pattern correlation between IO interannual and decadal ENSO sea level signatures in reconstructions $(>0.8)$, compared to reanalyses and WOD $(0.3$ to 0.6 ; Figure 4d), confirms the similarity of interannual and decadal ENSO sea level signatures in reconstructions. One plausible reason for this similarity is linked to the sea level reconstruction methodology, which projects the leading EOFs of global sea level over a long period using the tide gauge records. While the distribution of tide gauges is sufficiently dense to constrain the spatial pattern of decadal sea level variability in the western Pacific, the only long-lasting tide gauge record (Fremantle) in a region of strong variability in the $\mathrm{IO}$ is on the west coast of Australia [Church et al., 2004]. As the sea level in this region is influenced by the western Pacific variability at both interannual and decadal time scales, the decadal sea level pattern in the rest of the southern $\mathrm{IO}$ is likely to resemble the interannual pattern because of the EOF-based pattern reconstruction technique. Sea level variations in the WO and reanalyses have no such constraint, but the decadal variability in these products is characterized by the availability of in situ data (and wind forcing in reanalyses) which is poor over the 1960-2000 period in the entire southern IO (Figure S8). The tendency of reconstructions to produce interannual-like pattern is evident even when the analysis is performed over the recent data-rich period (1980-2010 or 1993-2010, not shown). Also note that results deduced from Figure 4 (ensemble mean average of reconstructions versus reanalyses) hold for individual pairs: reconstructions tend to emphasize the signal associated with decadal ENSO (and Modoki) in the southern tropical IO (Figures S4 and S5) and to reduce the amplitude of ENSO-independent signal in the southwestern IO (Figure S7) relative to the reanalyses they are derived from. Overall, the above analyses hence indicate that reconstructions may tend to accentuate ENSO-dependent signal in the $\mathrm{IO}$ and strongly underestimate ENSO-independent variability.

\section{Discussion}

Decadal sea level variations depicted in available gridded sea level data sets over the 1960-2010 period are generally consistent in the Pacific, with a typical standard deviation of 2-3 cm. The Pacific decadal sea level variability is dominated by two decadal climate modes. The decadal ENSO-related basin-scale sea level pattern in the Pacific ( $50 \%$ of variance, on average) is very consistent across products and similar to that depicted by satellite altimetry over the shorter period (1993-2013). Any of these products can hence be confidently used to describe ENSO-related Pacific decadal sea level variability. Our analysis confirms the decadal Modoki sea level imprint ( 20\% of variance, on average), suggested by BY2010 based on altimetry, over a longer 50 year period. The interproducts consistency for this mode is, however, weaker than that related 
to decadal ENSO fluctuations, with consistent signals mostly in the western tropical Pacific. The time evolution of this second mode is also quite uncertain before 1980, most likely because of the limited observational coverage and larger degree of uncertainty in wind forcing.

IO decadal sea level variations generally have a smaller amplitude $(1-2 \mathrm{~cm})$ than those in the Pacific and are far less consistent across the data sets. The oceanic bridge associated to ENSO between the western Pacific and west Australian coast discussed in previous studies [e.g., Feng et al., 2004, 2010; Lee and McPhaden, 2008, N2013] is robust across products. However, the transmission of (weak) decadal Modoki sea level signals in this region is more variable across the products. The atmospheric teleconnection between decadal ENSO and sea level variability in the southern tropical IO, suggested by Lee and McPhaden [2008], appears in reconstructions but is absent in other products. The uncertainties are even larger for intrinsic (Pacific independent) IO decadal sea level variability. Though most of the products suggest that a large fraction of $I O$ decadal sea level variance is independent from the Pacific, this Pacific-independent decadal sea level variability is highly variable across products.

This poor consistence is probably due to a data coverage that is insufficient to properly constrain IO decadal sea level variability. There are, for instance, not many multidecadal tide gauge records in the IO to constrain reconstructions, and in particular no records in the interior 10 , while many islands host records that span several decades in the western Pacific [Church et al., 2004, Figure 1]. On the other hand, sea level from reanalyses and WO is more dependent on in situ ocean profiles that can resolve variations in upper ocean heat content. As shown in Figure S8, while the western Pacific is being relatively well sampled since 1960, the southern IO has large gaps until the early 2000s. It is also to be noted that the IO decadal sea level variations (the signal we are interested in) are about twice weaker than in the Pacific (Figure 1a). On the other hand, there is a significant small-scale "noise" in IO sea level variability, for instance, associated with mesoscale eddies [e.g., Li and Han, 2015], leading to a lower signal-to-noise ratio in this basin.

Most of the past literature discussing IO decadal sea level variations largely relied on the analysis of numerical experiments using a single model framework [e.g., Schwarzkopf and Böning, 2011; Trenary and Han, 2013; Zhuang et al., 2013; N2013; Li and Han, 2015]. These experiments can only be validated to the short satellite altimetry data set or to the longer but relatively inconsistent reanalyses and reconstructions. Except off the west Australian coast, where the different data sets are generally consistent, this can cast some doubts on the reliability of the results discussed in these studies, knowing that surface wind stress decadal variability can also significantly differ between existing products [Nidheesh, 2017]. It is, for instance, difficult to conclude whether there is an atmospheric teleconnection to the Pacific-possibly associated to the links between the decadal IOD and ENSO modulations - that induces a decadal sea level response in the southern tropical IO, as suggested by Lee and McPhaden [2008], as this feature is only seen in reconstructions but not in reanalyses/WO. As pointed out above, the former indeed suffer from a very sparse coverage of long tide gauges in the $\mathrm{IO}$, while the latter are plagued by poor in situ data coverage and (for reanalyses) inconsistent estimates in decadal wind variations [N2013]. It is also currently difficult to assess whether there is an intrinsic decadal sea level variability in the $\mathrm{IO}$, or its pattern, confirming the view that $\mathrm{IO}$ decadal variability is a grey area [Han et al., 2014]. Future studies will hence be necessary to decipher whether some products can be trusted more than others, for example, by comparing these products with ocean profiles collected along multidecadal lines of the Ship of Opportunity Program in key regions such as the southern and southwest tropical IO. The CMIP database also offers an interesting opportunity to investigate whether coupled models can yield a more coherent view of IO decadal variability than current observation-based sea level data sets.

\section{References}

Annamalai, H., R. Murtugudde, J. Potemra, S.-P. Xie, P. Liu, and B. Wang (2003), Coupled dynamics over the IO: Spring initiation of the zonal mode, Deep Sea Res., Part II, 50(12-13), 2305-2323.

Ashok, K., S. K. Behera, S. A. Rao, H. Weng, and T. Yamagata (2007), El Niño Modoki and its possible teleconnection, J. Geophys. Res., 112, C11007, doi:10.1029/2006JC003798.

Balmaseda, M. A., K. Mogensen, and A. T. Weaver (2013), Evaluation of the ECMWF ocean reanalysis system ORAS4, Q. J. R. Meteorol. Soc., 139, $1132-1161$.

Behera, S. K., and T. Yamagata (2010), Imprint of the El Niño Modoki on decadal sea level changes, Geophys. Res. Lett., 37, L23702, doi:10.1029/ 2010 GL045936.

Bromirski, P. D., A. J. Miller, R. E. Flick, and G. Auad (2011), Dynamical suppression of sea level rise along the Pacific Coast of North America: Indications for imminent acceleration, J. Geophys. Res., 116, C07005, doi:10.1029/2010JC006759.

Carton, J., and B. Giese (2008), A reanalysis of ocean climate using simple ocean data assimilation (SODA), Mon. Weather Rev., 136, $2999-3017$. 
Church, J. A., and N. J. White (2011), Sea-level rise from the late 19th to the early 21st century, Surv. Geophys., 32, $585-602$.

Church, J. A., N. J. White, R. Coleman, K. Lambeck, and J. X. Mitrovica (2004), Estimates of the regional distribution of sea-level rise over the 1950 to 2000 period, J. Clim., 17, 2609-2625.

Cleveland, R. B., W. S. Cleveland, J. E. McRae, and I. Terpenning (1990), STL: A seasonal-trend decomposition procedure based on loess, J. Off. Stat., 6, 3-73.

Di Lorenzo, E., K. M. Cobb, J. C. Furtado, N. Schneider, B. T. Anderson, A. Bracco, M. A. Alexander, and D. J. Vimont (2010), Central Pacific el Niño and decadal climate change in the North Pacific Ocean, Nat. Geosci., 3(11), 762-765.

Dong, L., T. Zhou, A. Dai, F. Song, B. Wu, and X. Chen (2016), The footprint of the inter-decadal Pacific oscillation in Indian Ocean sea surface temperatures, Sci. Rep., 621251.

Fasullo, J. T., R. S. Nerem, and B. Hamlington (2016), Is the detection of accelerated sea level rise imminent?, Sci. Rep., 6, 31245.

Feng, M., G. Meyers, A. Pearce, S. Wijffels (2003), Annual and interannual variations of the Leeuwin Current at 32 $\mathrm{S}, \mathrm{J}$. Geophys. Res., 108(C11), 3355, doi:10.1029/2002JC001763.

Feng, M., Y. Li, and G. Meyers (2004), Multi-decadal variations of Fremantle sea level: Footprint of climate variability in the tropical Pacific, Geophys. Res. Lett., 31, L16302, doi:10.1029/2004GL019947.

Feng, M., M. J. McPhaden, and T. Lee (2010), Decadal variability of the Pacific subtropical cells and their influence on the southeast Indian Ocean, Geophys. Res. Lett., 37, L09606, doi:10.1029/2010GL042796.

Frankcombe, L. M., S. McGregor, and M. H. England (2015), Robustness of the modes of Indo-Pacific sea-level variability, Clim. Dyn. 45, 1281.

Hamlington, B. D., R. Leben, S. Nerem, W. Han, and K.-Y. Kim (2011), Reconstructing sea level using cyclostationary empirical orthogonal functions, J. Geophys. Res., 116, C12015, doi:10.1029/2011JC007529.

Hamlington, B. D., R. R. Leben, and K.-Y. Kim (2012), Improving sea level reconstructions using non-sea level measurements, J. Geophys. Res., 117, C10025, doi:10.1029/2012JC008277.

Hamlington, B. D., R. R. Leben, M. W. Strassburg, R. S. Nerem, and K.-Y. Kim (2013), Contribution of the Pacific decadal oscillation to global mean sea level trends, Geophys. Res. Lett., 40, 5171-5175, doi:10.1002/grl.50950.

Hamlington, B. D., M. W. Strassburg, R. R. Leben, W. Han, R. S. Nerem, and K.-Y. Kim (2014), Uncovering an anthropogenic sea-level rise signal in the Pacific Ocean, Nat. Clim. Change, 4, 782-785.

Han, W., J. Vialard, M. J. McPhaden, T. Lee, Y. Masumoto, M. Feng, and W. P. M. de Ruijter (2014), Indian Ocean decadal variability: A review, Bull. Am. Meteorol. Soc., 95, 1679-1703.

Köhl, A., and D. Stammer (2008), Decadal sea level changes in the 50-year GECCO ocean synthesis, J. Clim., 21, 1876-1890.

Kosaka, Y., and S.-P. Xie (2013), Recent global-warming hiatus tied to equatorial Pacific surface cooling, Nature, 501, $403-407$.

Lee, S. K., W. Park, M. O. Baringer, et al. (2015), Pacific origin of the abrupt increase in Indian Ocean heat content during the warming hiatus, Nat. Geosci., 8, 445-449, doi:10.1038/ngeo2438.

Lee, T., and M. J. McPhaden (2008), Decadal phase change in large-scale sea level and winds in the indo-Pacific region at the end of the 20th century, Geophys. Res. Lett., 35, L01605, doi:10.1029/2007GL032419.

Levitus, S., et al. (2012), World ocean heat content and thermosteric sea level change (0-2000 m), 1955-2010, Geophys. Res. Lett., 39, L10603, doi:10.1029/2012GL051106

Li, Y., and W. Han (2015), Decadal sea level variations in the Indian Ocean investigated with HYCOM: Roles of climate modes, ocean internal variability, and stochastic wind forcing, J. Clim., 28, 9143-9165.

Merrifield, M. (2011), A shift in western tropical Pacific sea level trends during the 1990s, J. Clim., 24, 4126-4138.

Meyssignac, B., M. Becker, W. Llovel, and A. Cazenave (2012a), An assessment of two-dimensional past sea level reconstructions over 19502009 based on tide gauge data and different input sea level grids, Surv. Geophys., 33(5), 945-972.

Meyssignac, B., D. Salas y Melia, M. Becker, W. Llovel, and A. Cazenave (2012b), Tropical Pacific spatial trend patterns in observed sea level: Internal variability and/or anthropogenic signature?, Clim. Past, 8, 787-802.

Moon, J.-H., Y. T. Song, P. D. Bromirski, and A. J. Miller (2013), Multi-decadal regional sea level shifts in the Pacific over 1958-2008, J. Geophys. Res. Oceans, 118, 7024-7035, doi:10.1002/2013JC009297

Neumann, B., A. T. Vafeidis, J. Zimmermann, and R. J. Nicholls (2015), Future coastal population growth and exposure to sea-level rise and coastal flooding-A global assessment, PLoS One, 10(3), e0118571, doi:10.1371/journal.pone.0118571.

Newman, M., G. P. Compo, and M. A. Alexander (2003), ENSO-forced variability of the Pacific decadal oscillation, J. Clim., 16(23).

Newman, M., et al. (2016), The Pacific decadal oscillation, revisited, J. Clim., 29, 4399-4427.

Nidheesh, A. G. (2017), Decadal and long-term sea-level changes in the tropical Indo-Pacific Ocean, PhD thesis, Goa Univ., Goa, India.

Nidheesh, A. G., M. Lengaigne, J. Vialard, A. S. Unnikrishnan, and H. Dayan (2013), Decadal and long-term sea level variability in the tropical indo-Pacific Ocean, Clim. Dyn., 41, 381-402.

Nieves, V., J. K. Willis, and W. C. Patzert (2015), Recent hiatus caused by decadal shift in indo-Pacific heating, Science, 349(6247), 532-535, doi:10.1126/science.aaa4521.

Nidheesh, A. G., M. Lengaigne, J. Vialard, T. Izumo, A. S. Unnikrishnan, and C. Cassou (2017), Influence of ENSO on the Pacific decadal oscillation in CMIP models, Clim. Dyn., doi:10.1007/s00382-016-3514-8.

Palanisamy, H., A. Cazenave, T. Delcroix, and B. Meyssignac (2015), Spatial trend patterns in the Pacific Ocean sea level during the altimetry era: The contribution of thermocline depth change and internal climate variability, Ocean Dyn., 65, 341-356.

Power, S., F. Tseitkin, V. Mehta, B. Lavery, S. Torok, and N. Holbrook (1999), Decadal climate variability in Australia during the twentieth century, Int. J. Climatol., 19(2), 169-184.

Rayner, N. A., et al. (2003), Global analyses of sea surface temperature, sea ice, and night marine air temperature since the late nineteenth century, J. Geophys. Res., 108(D14), 4407, doi:10.1029/2002JD002670.

Schwarzkopf, F. U., and C. W. Böning (2011), Contribution of Pacific wind stress to multi-decadal variations in upper ocean heat content and sea level in the tropical south Indian Ocean, Geophys. Res. Lett., 38, L12602, doi:10.1029/2011GL047651.

Serazin, G., T. Penduff, S. Gregorio, B. Barnier, J.-M. Molines, and L. Terray (2015), Intrinsic variability of sea level from global $1 / 12^{\circ}$ ocean simulations: Spatiotemporal scales, J. Clim., 28, 4279-4292.

Stammer, D., A. Cazenave, R. M. Ponte, and M. E. Tamisiea (2013), Causes for contemporary regional sea level changes, Annu. Rev. Mar. Sci., 5 , 21-46, doi:10.1146/annurev-marine-121211-172406.

Trenary, L., and W. Han (2013), Local and remote forcing of decadal sea level and thermocline depth variability in the south Indian Ocean, J. Geophys. Res. Oceans, 118, 381-398, doi:10.1029/2012JC008317.

Webster, P. J., A. M. Moore, J. P. Loschnigg, and R. R. Leben (1999), Coupled ocean-atmospheric dynamics in the Indian Ocean during 199798, Nature, 401, 356-360. 
Widlansky, M. J., A. Timmermann, and W. Cai (2015), Future extreme sea level seesaws in the tropical Pacific, Sci. Adv., 1, e1500560, doi:10.1126/sciadv.1500560.

Zhang, X., and J. A. Church (2012), Sea level trends, interannual and decadal variability in the Pacific Ocean, Geophys. Res. Lett., 39, L21701, doi:10.1029/2012GL053240.

Zhuang, W., M. Feng, Y. Du, A. Schiller, and D. Wang (2013), Low-frequency sea level variability in the southern Indian Ocean and its impacts on the oceanic meridional transports, J. Geophys. Res. Oceans, 118, 1302-1315, doi:10.1002/jgrc.20129. 